\title{
Timing and the Holding Periods of Institutional Real Estate
}

\section{David Collett ${ }^{1}$, Colin Lizieri ${ }^{2}$ and Charles Ward ${ }^{3}$}

Department of Land Management and Development

The University of Reading

Reading, UK

March, 2000

RG6 6AW

Tel: $+44(0) 1189318170$

Fax: +44 (0) 1189318172

\footnotetext{
${ }^{1}$ Department of Applied Statistics, The University of Reading

2 Department of Land Management and Development, The University of Reading

${ }^{3}$ Department of Land Management and Development, The University of Reading: Author for Correspondence, e-mail c.w.r.ward@rdg.ac.uk
} 


\title{
Timing and the Holding Periods of Institutional Real Estate
}

Key Words: real estate investment; holding periods; sales rate; proportional hazards.

\begin{abstract}
:
The literature on investors' holding periods for equities and bonds suggest that high transaction costs are associated with longer holding periods. Return volatility, by contrast, is associated with short-term trading and hence shorter holding periods. High transaction costs and the perceived illiquidity of the real estate market leads to an expectation of longer holding periods. Further, work on depreciation and obsolescence might suggest that there is an optimal holding period. However, there is little empirical work in the area. In this paper, data from the Investment Property Databank are used to investigate sales rate and holding period for UK institutional real estate between 1981 and 1994. Sales rates are investigated using the Cox proportional hazards framework. The results show longer holding periods than those claimed by investors. There are marked differences by type of property and sales rates vary over time. Contemporaneous returns are positively associated with an increase in the rate of sale. The results shed light on investor behaviour.
\end{abstract}

\section{Acknowledgements:}

We are very grateful to Investment Property Databank and, in particular, to Tony Key, for making the acquisition, sale and return data available. The views expressed in this paper are of the authors alone and should not be taken to represent the opinions of IPD. A preliminary version of this paper with a smaller data set was presented at the ESRC-funded seminar on property finance organised by the Property Economics and Finance Research Network in 1999. We acknowledge the many helpful comments of participants at that seminar and also the comments received at the American Real Estate Society annual meeting in Santa Barbara, California, in April 2000. 


\section{Timing and the Holding Periods of Institutional Real Estate}

\section{Introduction}

In analysing the investment worth of commercial real estate, knowledge of the likely holding period is important. Cashflow based investment appraisals impose a holding period assumption (which may be determined by forecast horizon). Nonetheless, the choice of an appropriate benchmark interest rate (for example, the government security with the appropriate maturity) should be determined by the most probable holding period. Similarly, asset allocation decisions should be mindful of holding periods, and of systematic differences in holding periods between different asset classes and sub-classes. Intuitively and anecdotally, commercial real estate has a much longer holding period than other investment assets. This may be attributed to transaction costs, illiquidity and the institutional characteristics of real estate as an investment asset.

The motivation for this paper is to examine whether there are any systematic influences on the holding period of institutional investors. We would expect that in periods in which there was liquidity in the real estate market, transaction costs would effectively be lower and, therefore, holding periods would be less. We would also expect to find some systematic differences between the holding periods of different types of real estate. For example, offices are, arguably, more homogenous than large shopping centres; there are entry barriers to investment in the latter due to large lot size, reducing liquidity. Accordingly, we might expect that the holding period for offices would be lower. We might expect to find some systematic effects as properties depreciate (proxied by the time elapsing since date of purchase). We might expect that there might be a tendency for newer properties to be sold when the market was illiquid and that old properties would be sold during periods in which the market was liquid. Finally we were curious to see if there was any additional effect caused by the 1990 real estate 'crisis'. The switch from a prolonged boom to a sudden down-turn was extremely important within the UK real estate market and 1990 marked several changes - banks cut back sharply on lending, market rents declined (at least in London) in nominal terms for the first time within living memory.

This paper investigates the holding period of commercial real estate owned by UK institutional investors, using a proportional hazards framework. It examines whether there are any systematic differences between the holding periods of different types of real estate and whether the holding period is influenced by market conditions. The next section discusses the theoretical literature on holding periods and the implications of this literature for real estate. Section three considers the definition and measurement of holding period and sets out the methodology employed in the study. Next, empirical results are set out. Finally, the paper concludes with a discussion of implications and avenues for future research. 


\section{Theoretical Framework}

Investment fund managers traditionally consider two approaches to adding value to their fund performance: stock selection and timing. Within stock selection, methods range through fundamental and 'technical' analysis to systematic portfolio-based techniques. Timing takes in approaches as diverse as ad hoc decisions to switch sectors and the more systematic methods of tactical asset and dynamic asset allocation. These approaches can be derived within the framework of modern portfolio theory that asserts that, if capital markets are efficient, fund managers will find it difficult to add value to the performance of their fund on a persistent basis.

In applying portfolio theory, attention must be paid to the holding period of assets and the investment horizon of investors. There is a body of evidence relating to stocks (and, to a lesser extent, bonds) that suggests that transaction costs influence holding periods. Specifically, high transactions costs (generally proxied by bid-ask spreads) are associated with longer holding periods. Theoretical and empirical backing for this is provided by Demsetz (1968), Tinic (1972), Amihaud \& Mendelson (1986), Bhide (1993), Umlauf (1993) and Atkins \& Dyl (1997). Amihaud and Mendelson propose that assets with higher bid-ask spreads would, in equilibrium, be held in portfolios by investors who expect to hold securities for a long time. Constantides (1986) concludes that investors 'accommodate transaction costs by drastically reducing the frequency and volume of trade' (p. 859). Hess (1991) suggests that households, faced with retail transaction costs, trade less than they would with wholesale costs. Accordingly, they hold portfolios that do not reflect current prices and expected returns. Their portfolios are thus sub-optimal and bear large amounts of uncompensated, diversifiable risk.

Atkins \& Dyl (1997) extend the empirical research by considering the effects of firm size, bid-ask spread and volatility of returns on holding period of properties, for a sample of over 2,000 NASDAQ firms and 500-1,100 NYSE firms over the period 1981-1993. Return volatility is included as an indicator of short-term trading, information asymmetry and the effect of omitted variables that change between time periods. They expected a positive relationship between volatility and trading and, hence, a negative relationship between volatility and trading period. They suggest that larger firms are followed by more analysts, reducing divergence of opinion and hence trading volume. Median holding periods over the full sample period were 3.4 years for NASDAQ and 2.4 years for NYSE, these averages concealing considerable stock and year variations. Their regression results confirmed a highly significant positive relationship between holding period and both spread (as a proxy for transaction costs) and firm size. They also found the expected negative relationship between price variability and holding period. 
Given the high transactions costs associated with commercial real estate relative to other capital market assets and the perceived illiquidity of the market, in part due to entry barriers, the expectation would be that holding periods for commercial real estate would be much greater than for stocks and bonds. However, the private nature of most transactions, real estate's heterogeneity and lower levels of institutional investment might be taken to imply information asymmetry and, hence, bring an expectation of more frequent trading. Information asymmetries and divergence of expectations are most likely to occur in downturns in the market - when, typically, there are few transactions to provide evidence. The relationship between returns and holding period in real estate markets is, thus, likely to prove complex.

While capital market research has focused upon timing and portfolio rebalancing, received wisdom in the asset management of real estate investors suggests that stock selection is more important than timing decisions. This belief is partly an updated tradition in property investment that good investments in the real estate market come from relating property performance to the location of the property. However, it would be wrong to imply that real estate investors do not recognise that the timing of property investment can have an impact on the performance of property. Investors and researchers do generally recognise that investing in real estate requires consideration of the effect of economic and physical depreciation, a belief that implicitly determines that the property has to be sold at an optimal time to realize its maximum contribution to portfolio performance.

Other esearchers (e.g. Williams, 1997) have modelled the re-development options inherent in any property and add the embedded asset to the worth of the property. This option, to some extent, becomes more valuable as the value of the property in its existing use falls relative to newer properties. Sale of the existing property means that the former owner has foregone the right to exercise the redevelopment option (although the value of the option ma be embedded in the sale price to some extent). Option pricing theory tells us that the option value increases as uncertainty (volatility of returns) increases. Therefore the redevelopment of older property (and hence the sale of the asset) would tend to be delayed if uncertainty increased, with a consequent increase in holding period.

In a recent research project (Gibson, Rowley and Ward, 1996), investors were interviewed about their perception of the effects of urban design on the performance of real estate investment. It emerged both in personal interviews and focus group discussion that investors buying or developing new real estate tended to have a holding period in mind from the start. Indeed in specific cases, investors suggested that their investment decision included the horizon at which the property would be sold.

In some cases, e.g. offices, this decision appeared to be related to the depreciation or obsolescence factor identified by Baum (1990) but in the case of retail property, the decision was more complicated. One investor hypothesised that shopping centres would gain value as the as centre became more established. This would result from direct and active management in getting the right tenants into the centre and controlling the use and actions of the tenants so that a high quality and successful profile was established. 


\section{Institutional Characteristics of the Real Estate Market}

In the UK, the predominant form of leasing contracts under which commercial real estate is let is a lease of 15,20 or 25 years which allows for rents to be adjusted at intervals of five years. The value of properties therefore depends on the rent being paid on the properties and the period that remains until the next rent review. The implications for property appraisal is that at the rent reviews, when rents are revised and set, the owners perceive that the uncertainly of property investment is at its lowest, since a new level of rents is guaranteed for the longest possible period.

Whereas most commercial property will be most valuable soon after the building is fully let, the same argument does not apply to shopping centres, which need longer to build up a market profile. With shopping centres, successful trading by tenants will be translated into higher rents fixed at the first rent review period (at, say, five years after initial development). At the second review (ten years from initial development), the policies of the active manager/owner will be fully recognised in the rents set. The argument advanced therefore implies that investors will hold retail property for longer periods than other types of real estate because it will take longer for active management of the shopping centre to have an impact on the negotiated rental levels and the resultant values.

The alternative hypothesis is that investors will sell the property when they sense that the achievable price is maximised. The source of the price changes will be partly the idiosyncratic value achieved by active management and partly reflect the state of the market in general. If real estate investors are driven more by opportunistic factors than their strategic decisions, and if they were successful in forecasting the state of the market, the volume of sales would depend more on the returns from the market and less on the time they had held the property.

\section{Measuring The Holding Period}

Given the frequency of trading in equity markets, transaction volume provides a useful indicator of holding period. In the stock market literature, the holding period in any period is typically defined as shares outstanding in that period divided by the trading volume (Atkins and Dyl (1987). Other studies - such as Hess (1991) - simply use the trading volume as a proxy. It would be possible to apply this methodology to real estate investment. Preliminary results from a recent survey of major institutional investors ${ }^{4}$ suggest that, on average, investors expected to deal on $19 \%$ of their real estate portfolio in any one year. This provides an initial crude estimate of average holding period of around 51/4 years. Weighting the sample by capital value of portfolio produces a slightly higher estimate of six years.

\footnotetext{
${ }^{4}$ We are grateful to Neil Crosby and Pat McAllister for making the survey results available. The estimates are by the authors and do not necessarily reflect the views of the IPF or of the research team.
} 
There are a number of drawbacks to such an approach. Firstly, such implied transactions figures may mask the fact that a number of assets may trade rarely and have long holding periods, whereas others trade frequently. Secondly, transaction volumes may fluctuate greatly from year to year, reflecting market conditions and other explanatory factors. These confusing variations are likely to be more problematic in real estate markets than in equity markets where, as seen above, the holding periods are much lower.

Such issues become more acute where one has actual sales data. In the data set employed in this study, we have information on actual sales of property from the Investment Property Databank (whose database is reported to account for some $70 \%$ of the UK institutional property market). Since we have both the year of purchase and the year of sale, we can work out an individual holding period for each such observation. However, the average holding period (whether mean or median) would be misleading, since we have no information on properties that were unsold over the period. Statistically, such data is described as censored and analysis requires care and rigour.

A set of statistical models have been developed that deal with the analysis of survival data (Collett, 1994). These models have their origins in industrial engineering (where they are used to estimate the useful lives of machines or components) and in biomedical sciences (used, for example, to describe survival times from particular types of medical procedure). They have been used in a number of economic problems concerning duration data, notably in the field of unemployment (for an early, but useful, review see Kiefer, 1988). An important application comes from the modelling of sources of "risk" - for example of mortgage default - using a proportional hazards framework and the regression technique developed by Cox.

Real estate applications of the proportional hazards technique include Lane et al. (1986) who use the Cox model to analyse bank failure; Quigley (1987) who examines housing mobility and mortgage prepayment; Kluger \& Miller (1990) who model time on the market for residential sales; Vandell et al. (1993) who estimate hazard functions for home loan defaults based on loan terms and price movements over time; and Simons (1994) who models industrial real estate mortgage default. As can be seen, the majority of such studies use housing or residential mortgage data. The development of proportional hazards techniques for assessing mortgage default and prepayment has been important in the evolution of pricing models for the mortgage backed securities market.

In summary, the proportional hazards framework models the rate of some event (e.g. sale of an asset) $t$ periods after a base date (e.g. date of purchase), $\lambda(t)$. This quantity, which is widely referred to as the hazard function, is, in this context, the instantaneous rate of the event at time $t$, given that the event has not occurred prior to $t$. The function is an approximation to the probability of the event in the $t^{\prime}$ th period, given that the event has not occurred at the start of the period: for example sale of an asset that was unsold at the start of a year. 
Our analysis is based on the Cox regression model for the rate at time $t$ subject to the value of two (categorical) variables $\mathrm{s}_{\mathrm{i}}$ and $\mathrm{p}_{\mathrm{j}}$ written $\lambda_{i j}(t)$. According to this model,

$$
\lambda_{i j}(t)=e^{\left(s_{i}+p_{j}\right)} \lambda_{0}(t)
$$

where $\mathrm{s}$ is the effect of $\mathrm{i}^{\prime}$ th category of variable $\mathrm{s}, i=1,2 \ldots$ and $\mathrm{p}$ is the effect of the $\mathrm{j}$ 'th category of variable $\mathrm{p}, j=1,2, \ldots$

In our example, $s$ is real estate sector and $p$ is year of purchase. By convention, we take $\mathrm{s}_{1}=\mathrm{p}_{1}=0$ and so $\lambda_{0}(\mathrm{t})$ is the rate of sale for a reference or baseline observation. In our model this is a standard retail property purchased in 1981. Often $\lambda_{0}(t)$ is called the baseline hazard function. The exponential term therefore quantifies how the sale rate is affected when a property of a different sector is purchased, or when the year of purchase is other than the first.

\section{Data and Results}

It is useful to re-state formally the questions we are addressing in this study, together with the results that might plausibly be expected.

(a) What is the best estimate of the holding period for real estate ?

(The holding period of real estate may be significantly longer than that for equities or bonds because of the less liquid market and the higher transaction costs.)

(b) Are there any significant differences between the holding period of property of different type or size?

(The holding period of large shopping centres will be longer than that for offices because of the institutional characteristics of the marketing potential for shopping centres, and because shopping centres are traded in a thinner market than other property-types).

(c) Are the estimates reasonably stable over time or are they subject to sudden and inexplicable changes from one year to another?

(The year of purchase might influence the selling decision as if property were bought in boom periods, investors might be reluctant to sell it in periods in which book losses might be recorded).

(d) Is the holding period ( or the propensity to sell a property) influenced by the state of the market?

( Holding periods would be expected to decline during periods of greater liquidity and rise during periods of less liquidity).

(e) Was there a sea-change that affected investors' behaviour caused by the UK property crisis of 1990 ?

(One might expect that the crisis has had a significant impact (above that caused by the low returns recorded by the real estate market in that and subsequent years). 
To provide an initial benchmark analysis of transactions-based estimated holding periods, we use published data from Investment Property Databank. The Property Investors Digest (IPD, various) records the average number of properties held on the database (categorised, for example, by sector) and also the number of properties sold in any one year. As widely discussed, the Databank is not static - the historic numbers change from one Digest to another as Funds join (and, in a few instances, leave) the Databank. Figure 1, below, shows the implied holding period, by sector, based on this data, for the period 1984-1998. Following the equity market literature, the implied holding periods are calculated as:

$$
\mathrm{HP}_{\mathrm{t}}=\frac{\left(\operatorname{Pr}_{\mathrm{t}}+\operatorname{Pr}_{\mathrm{t}-1}\right) / 2}{\operatorname{Tran}_{\mathrm{t}}}
$$

where $\operatorname{Pr}_{t}$ is the number of properties in the Databank at the end of year $t$ and $\operatorname{Tran}_{t}$ is the number of sales within year $t$ The numerator is a proxy for the average number of properties held over the year as a whole.

Figure 1: Implied Transaction-Based Holding Periods, IPD 1984-1998

\begin{tabular}{|r|c|c|c|c|c|c|c|c|c|c|c|c|c|c|c|c|}
\hline & 1984 & 1985 & 1986 & 1987 & 1988 & 1989 & 1990 & 1991 & 1992 & 1993 & 1994 & 1995 & 1996 & 1997 & 1998 & Mean \\
\hline Standard Shops & 19.4 & 19.2 & 15.0 & 8.8 & 8.5 & 11.4 & 20.9 & 11.9 & 15.7 & 9.4 & 9.2 & 10.1 & 9.3 & 7.1 & 3.9 & 12.0 \\
\hline Shopping Centres & 43.5 & 56.1 & 26.5 & 21.1 & 13.3 & 14.8 & 37.6 & 33.9 & 20.4 & 12.5 & 20.0 & 11.7 & 14.3 & 11.3 & 5.5 & 22.8 \\
\hline Retail Warehouses & -- & -- & 36.0 & 12.5 & 24.2 & 19.9 & 35.8 & 27.2 & 25.3 & 11.7 & 13.9 & 13.8 & 12.9 & 9.9 & 6.3 & 19.2 \\
\hline Offices (All) & 28.8 & 22.1 & 17.6 & 8.7 & 8.6 & 11.2 & 20.2 & 20.2 & 17.9 & 11.9 & 10.3 & 9.9 & 8.4 & 5.8 & 3.5 & 13.7 \\
\hline Industrial (All) & 20.5 & 13.8 & 9.0 & 4.8 & 5.6 & 11.0 & 17.7 & 20.9 & 20.1 & 12.7 & 9.6 & 9.7 & 8.8 & 7.4 & 5.3 & 11.8 \\
\hline Other & 22.6 & 21.7 & 16.1 & 13.1 & 10.9 & 18.4 & 22.7 & 18.4 & 13.9 & 9.3 & 10.2 & 8.3 & 13.6 & 10.1 & 5.5 & 14.3 \\
\hline All Property & 22.6 & 19.4 & 14.5 & 8.2 & 8.3 & 11.9 & 20.7 & 16.1 & 17.0 & 10.6 & 10.0 & 9.9 & 9.5 & 7.2 & 4.2 & 12.7 \\
\hline
\end{tabular}

Ignoring the rogue results for the early years covered by the Databank, the average holding period between 1984-1996, at around 13 years, would probably be close to received wisdom, albeit on the high side. There are striking variations, however, over time. Thus, sales volume is relatively low in the early 1990s real estate slump, driving up notional holding periods, which then fall rapidly as the market improves through the decade.

These notional figures imply holding periods that are more than twice as large as those implied by portfolio turnover figures from the IPF survey, reported above. Even considering just the last five years, median holding periods exceed the investors' own estimates. How might this anomaly arise? One reason might be that funds have large numbers of older properties in their portfolio that are not subject to turnover. This might be because they are flagship or trophy properties or because they are too small to be worth trading. Furthermore, properties acquired more recently might be subject to more regular investment appraisal, be more liquid and hence be more likely to be traded. As a result, aggregate holding period estimates would overstate the holding period of currently traded properties. Since information on holding period is important for establishing investment horizons and benchmark interest rates, it is important to take into account the properties that are traded. 
The unpublished data used in this study was provided by Investment Property Databank. It consists of records of properties acquired by funds between 1981 and 1998, together with a date sold (should a transaction have occurred) and information on sector. Confidentiality constraints meant that other classificatory data was not available. In total, records of 13,405 acquisitions were available. Comparisons are made difficult by the dynamic nature of the Databank, but the data represents around $81 \%$ of the acquisitions made over that period ${ }^{5}$.

In the study period, 1981-1998, 5,736 of the sample properties acquired were also sold (43\% of the sample). This represents around $28 \%$ of sales recorded by IPD over this period. Since we know the time between acquisition and sale for those properties sold, but have a substantial proportion of our sample unsold at the end of the period, the data is (right) censored and hence appropriate for analysis using the survival / hazards framework..

As noted above, we specify a proportional hazard function using the Cox regression model with the baseline hazard function, $\lambda_{0}(t)$, set for a retail property purchased in 1981 . The exponential term in Equation (1), therefore, quantifies how the sale rate is affected when a property of a different sector is purchased, or when the year of purchase is other than the first. The suitability of the proportional hazard model was tested in advance of model fitting by examining log cumulative hazard plots: these proved satisfactory. After fitting the model, Cox Snell residuals were obtained. A log cumulative hazard plot of these residuals proved to be a straight line with unit slope passing through the origin. On the basis of these diagnostics, the fitted model is satisfactory (see Collett, 1994 for details of testing procedures). In our analysis, both sector and purchase year were found to be highly significant $(\mathrm{p}<0.001)$. We therefore conclude that sale rate depends on both sector and purchase year.

Figure 2 shows maximum likelihood estimates for the sector variables. The risk ratio compares the sales rate for the sector to the standard shop baseline. A value less than one implies a lower risk of sale and, hence, a longer holding period. Marked differences emerge. Smaller offices (current value less than $£ 1.5$ million) have the highest sales rates: all other sectors have sales rates below those of standard shops. Properties with the largest lot size (shopping malls, large offices) have the longest holding periods. This may reflect liquidity (entry barriers restrict the number of potential purchasers), the trophy nature of such buildings or, in the case of shopping centres, the fact that value is only maximised after a period of management. The retail warehouse market developed over the analysis period. In the property slump of the early 1990s, retail warehouse continued to generate positive returns, which may explain the lower sales rate. In the downturn, industrial property outperformed retail and office markets.

Translating the results into median holding times (for a baseline 1981 acquisition) indicates that small offices have the shortest average holding period (10 years) followed by industrial units (11 years). The other sectors have median holding periods of around 12 years, with the exception of shopping centres, which are held, on average for an additional two years.

\footnotetext{
5 The "missing" acquisitions are made up predominantly of sector/property types not included in our data and acquisitions by funds no longer included in the IPD databank.
} 
Figure 2: Maximum Likelihood Estimates (Standard Shops as Base Case)

\begin{tabular}{|c|c|c|}
\hline Sector & Parameter & Risk Ratio \\
\hline Shopping Centres & $-0.3288^{* *}$ & 0.720 \\
\hline Retail Warehouses & -0.0469 & 0.954 \\
\hline Small Offices & $0.2710^{* * *}$ & 1.311 \\
\hline Large Offices & $-0.0611^{*}$ & 0.941 \\
\hline Industrials & $-0.0824 * *$ & 0.921 \\
\hline
\end{tabular}

Note: * indicates significantly different from zero at $10 \%$, $* *$ at $5 \%$ and $* * *$ at $1 \%$ level respectively using the Wald $\chi^{2}$ test.

Figure 3 plots maximum likelihood estimator risk ratios against year of purchase. Sales rates for properties acquired between 1982 and 1984 are statistically similar to the baseline rate. After 1985, there is a marked jump in the sale rate, with the risk ratio rising to around 1.4. There is a further jump in 1993 where the risk ratio exceeds 2. The 1993 effect can be seen in overall transactions volume on IPD (note the fall in holding periods in Figure 1, above). However, overall transaction volume falls sharply in the period 1990-1992, reflecting the difficult market conditions. That this does not appear in the proportional hazard results provides interesting information on the behaviour of markets in downturns.

Figure 3: Analysis of MLE Risk Ratios Classified by the Year of Purchase.

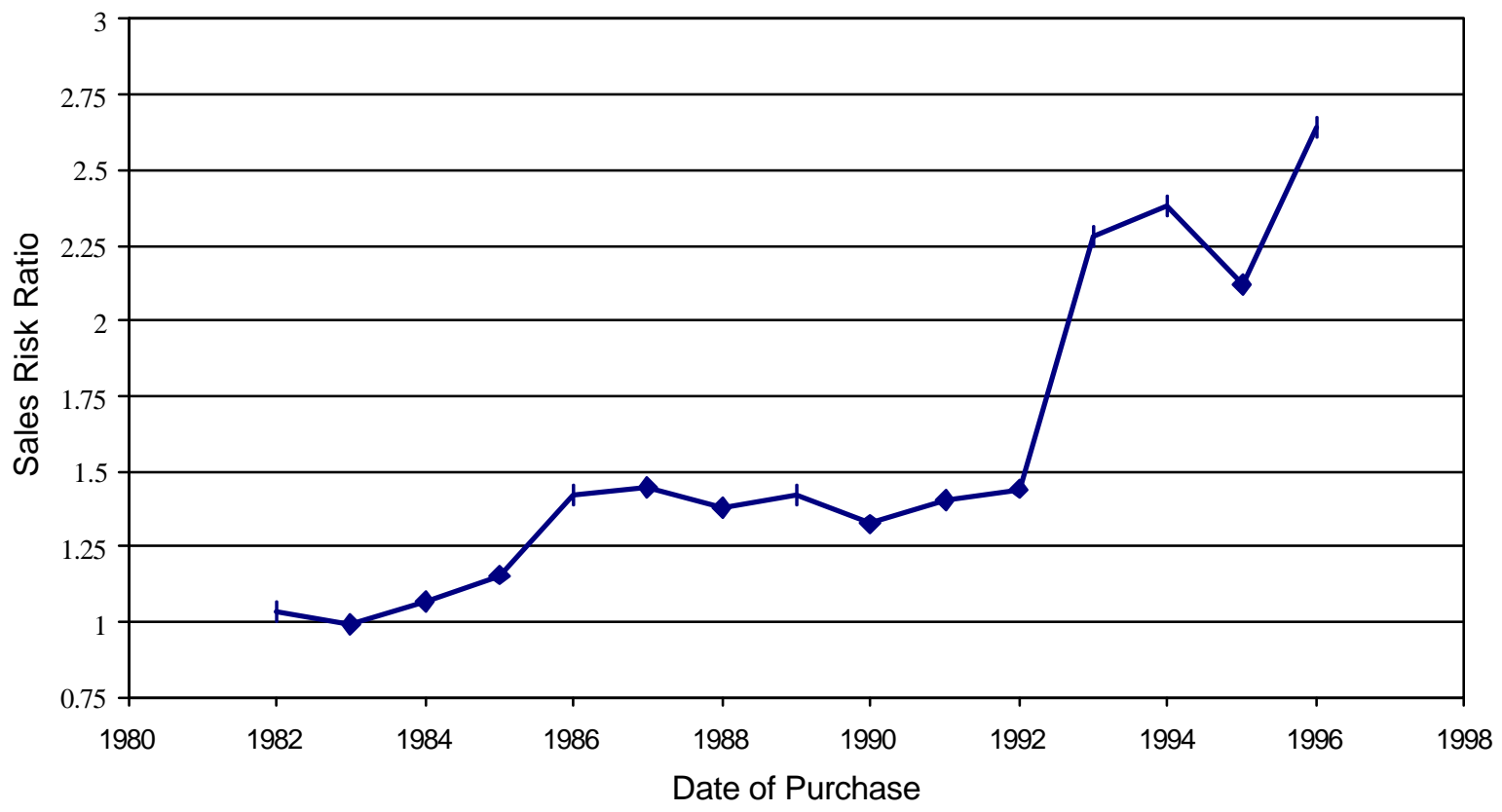


The impact of year of purchase may be shown more clearly by the median holding period: that is the time beyond which $50 \%$ of the properties are sold. Figure 4 shows estimated median holding times for a property in the retail sector purchased in years 1981 - 1997. We see that these holding periods average 12 years for properties purchased between 1981 and 1985 , but then reduce by some two years. In contrast, the estimated holding periods based on aggregate IPD transactions fall up to 1988 and then rise sharply over the early years of the 1990s, during the real estate slump, before falling again. The estimates based on the IPD aggregates reflect the fall in overall transactions over the recession.

Figure 4: Estimated Median Holding Time for Retail Properties Purchased Between 1981 and 1997

\begin{tabular}{|l|c|c|c|c|c|c|}
\hline Year & 1981 & 1982 & 1983 & 1984 & 1985 & 1986 \\
\hline Median & 12 & 11 & 12 & 11 & 11 & 9 \\
\hline
\end{tabular}

\begin{tabular}{|l|c|c|c|c|c|c|}
\hline Year & 1987 & 1988 & 1989 & 1990 & 1991 & 1992 \\
\hline Median & 9 & 9 & 9 & 10 & 9 & 9 \\
\hline
\end{tabular}

\begin{tabular}{|l|c|c|c|c|c|c|}
\hline Year & 1993 & 1994 & 1995 & 1996 & 1997 & 1998 \\
\hline Median & 7 & 7 & 7 & 7 & 8 & $*$ \\
\hline
\end{tabular}

Note: 1998 figure not reported as standard error too large for meaningful estimate

That median holding times fall in the Cox model suggests that properties purchased during that period were sold on - either due to profit taking as markets recovered in the mid-1990s or, during the downturn, because they were more liquid in nature (funds might be unwilling to purchase assets considered illiquid while markets are performing badly). Recall that theory suggests that information asymmetries (likely to be at their greatest in recessions) should lead to more sales, and hence falling average holding periods, consistent with our results. However, funds might be unable to find buyers for older, secondary property and for larger, less liquid assets - explaining both the disparity between the proportional hazard results and observed sales volume and the sectoral differences shown above.

The estimated baseline rate of sale, $\lambda_{0}(t)$ in the Cox regression model, indicates how the rate of sale for a property in the retail sector and purchased in 1981 changes over the years. This function is shown in Figure 5 from which we see that the sale rate typically increases over time, other factors being constant. 
This figure also shows that the sale rate does not increase much for the two years around holding times of ten and fifteen years, possibly related to the second and third rent reviews ${ }^{6}$, or to a non-linear depreciation rate. There also appears to be quite a marked increase in this rate 14 years after purchase. However, given that we have a comparatively short analysis period (such that there are only nine properties sold this far after purchase), this sale rate is imprecisely estimated.

Figure 5: Instantaneous Rate of Sale Categorised by Year Since Purchase.

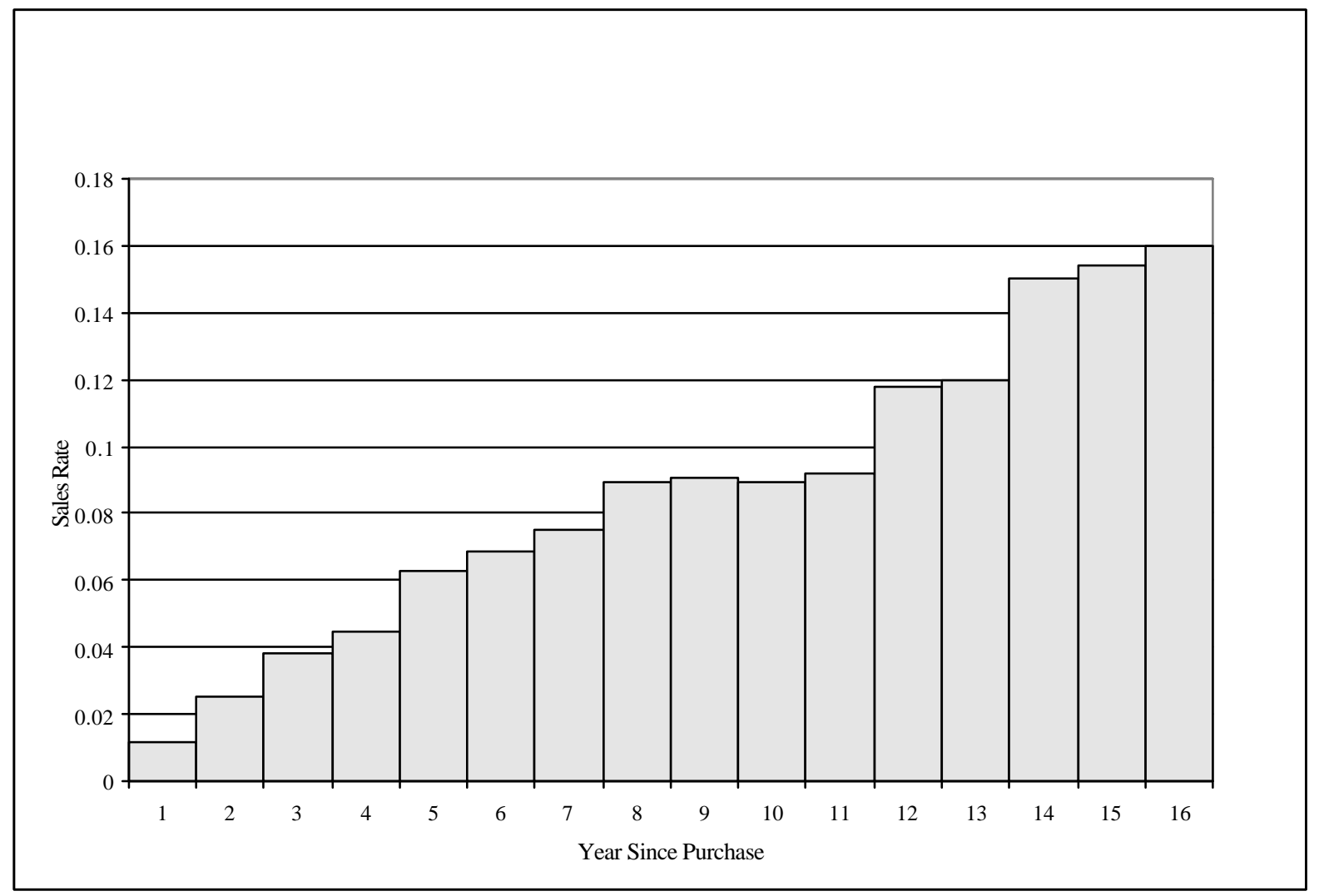

Data on the returns from the IPD sector indices in each of the years 1982 - 1998 were also available. This enabled us to investigate the dependence of rate of sale on return. Since return changes over the holding period of a property, we cannot include this in our model in the same way as for variables such as sector that are constant over this period. Instead we regard return as a time dependent variable and include it in the model in the manner described in Collett (1994, Chapter 7).

We found that the return in a given year has a very highly significant impact on sale rate in that year $(p<0.0001)$; the higher the return, the greater is the sale rate. There is evidence in the data that this effect is not linear (quadratic), in that the effect of return on sale rate increases as return increases.

\footnotetext{
${ }^{6}$ This would, however, assume that properties were bought in the year they were first let or immediately on review. It would also imply that reversionary values might be mis -estimated in the market.
} 
In some years, return was negative and so we investigated whether the effect of return on sale rate was essentially explained by whether return was positive or negative. Although this binary categorisation led to return having a clear impact on sale rate, it could not explain as much variation in the data as the term corresponding to the actual return values. Moreover, including return in the model does not affect conclusions about the effect of purchase year and sector on the rate of sale. This is consistent with the expected answer to question (d) above.

The implication of this result is that sales (and, by implication, purchase) decisions are affected by contemporaneous increases in value rather than by future prospects. The return in the year after sale is still significant $(\mathrm{p}=0.015)$ but the lower explanatory power suggests that this is just an autoregressive effect. This suggests that market liquidity is driven, in large measure, by short run sentiment.

We also investigated whether investor behaviour changed as a result of the property downturn by contrasting the sales rates in the period up to 1990 with those after that date (Question e above). The 1990 point has a highly significant effect $(\mathrm{p}<0.001)$ - but one that was unexpected. In the post-1990 period, sales rate falls subject to the other hazard variables. This result is persistent, whether or not returns are included in the model. This effect will be the subject of further investigation. At this stage, we believe it implies a change in the composition of sales. This is likely to result in further divergence in the holding periods of buildings in different sectors and of different ages.

\section{Conclusions}

Knowledge of the expected holding period of commercial real estate assets is important for a number of reasons. Investment appraisal to determine asset worth requires specification of an analysis period; determination of an appropriate benchmark interest rate requires specification of appropriate bond maturity. Furthermore, if holding periods vary according to the characteristics of the asset and to market conditions, this information should be incorporated in analysis. Conventional measures of holding periods are either anecdotal or rely on a measure based on volume of transactions. The latter measure is flawed since some assets may trade more regularly than others, while some assets remain unsold throughout the period of analysis: that is, the data is censored. This makes use of statistical procedures developed for the analysis of survival data highly appropriate.

The data used in the analysis presented here is of properties acquired by funds contributing to the Investment Property Databank in the period 1981 - 1998. Thus the properties in the sample represent the type of real estate that institutional investors have been appraising in recent years. The results may, thus, be considered valid for current analysis of investment decisions. Other properties held by funds may have different characteristics and, hence, results based on aggregate sales may be inappropriate. 
Theoretical and empirical research relating to equities suggests that high transactions cost should result in fewer transactions and longer holding periods. It is further suggested that information asymmetries and uncertainty (evidenced in the market place by price volatility) lead to more transactions and resultant shorter holding periods. A priori, this would point to considerably longer holding periods for real estate, in part offset by uncertainty. However, the anticipated longer holding periods may lead to investors declining to sell in poor markets (characterised by uncertainty through lack of transactions information).

In difficult markets, some properties will exhibit greater liquidity - typically, those purchased recently. Thus we anticipate that our sample would behave differently from the aggregate IPD index. Investors able to exploit uncertainty may be able to acquire bargains in poor markets and realise profits in recovery. Thus we would expect to see properties purchased in the real estate slump exhibiting faster sales rates (and shorter holding periods) than other properties.

These prior expectations are largely confirmed by the results of the Cox proportional hazards regressions. The baseline hazard function reveals that the median holding period varies between eight and twelve years. This is far greater than the holding periods reported for equities (although the growth of index tracking funds may push stock holding periods upwards), but less than the aggregate point estimates calculated by comparing transactions to properties held on the IPD databank (The expected answer to Question (a), above, is therefore confirmed). The implied holding periods are longer than those implied by survey data from funds who report a greater degree of turnover in their portfolios than is evident from the data. The holding period falls significantly for properties purchased in the real estate recession, which is consistent with a profit-taking thesis ${ }^{7}$

Examination of the baseline hazard function reveals features with reflect the institutional structure of the market and the characteristics of the asset. Sales rates fall or plateau around ten and fifteen years, which would coincide with the timing of the second and third rent reviews. There is a sharp increase in sales as the holding period exceeds fourteen years, which may relate to years unexpired on the lease and appraisal attitudes towards such properties. This latter may be associated with depreciation and obsolescence. That retail property in our sample has a longer holding period than smaller office or industrial property may reflect the importance of location and the lower significance of physical obsolescence for town centre shops. (This is consistent with our a priori expectations to Question (b), above).

The research reported here is exploratory in nature. Further causal analysis is constrained by the nature of the data and the limited range of explanatory variables. The limited time series and lack of high frequency data for commercial real estate markets, allied to the long time taken to complete a sale or purchase somewhat limit the scope for more detailed analysis. Nonetheless, we believe that the results reported here represent an advance over aggregate sales-based proxies of holding periods and contribute to a better understanding of investor behaviour.

\footnotetext{
${ }^{7}$ Although the sample period is too small to be definitive, the sharp drop in holding periods for properties purchased in 1993 and 1994 may reflect profit taking during the surge of institutional funds into real estate - the so-called "wall of money" in early 1994.
} 


\section{References}

Amihud Y and Mendelson H (1986), "Asset Pricing and the Bid-Ask Spread", Journal of Financial Economics, 17, 223-249.

Atkins A and Dyl E (1997), "Transactions costs and holding periods for common stocks", Journal of Finance, March, 52, 1, 309-325.

Baum A (1990) Property Investment, Depreciation and Obsolescence London: Routledge

Bhide A (1993), "The Hidden Costs of Stock Market Liquidity", Journal of Financial Economics, 34, 31-51.

Collett, D (1994) Modelling Survival Data in Medical Research, London: Chapman \& Hall..

Constantinides G (1986) "Capital Market Equilibrium with Transaction Costs" Journal of Political Economy 94, 842-862.

Demsetz H, (1968), "The Cost of Transacting", Quarterly Journal of Economics, 82, 33-53.

Gau G W and Wang K, (1994), "The tax-induced holding periods of real estate investors: theory and empirical evidence", Journal of Real Estate Finance and Economics, 8, 1, 71-86.

Hess A (1991), "The Effect of Transaction Costs on Households' Financial Asset Demands" Journal of Money, Credit and Banking, 23, 383-409.

Kiefer N (1988) "Economic Duration Data and Hazard Functions Journal of Economic Literature, 26, 646-679.

Kluger B and Miller N (1990) "Measuring Residential Real Estate Liquidity" Real Estate Economics, 18, 2, 145-149.

Lane W, Looney S and Wansley J (1986) "An Application of the Cox Proportional Hazard Model to Bank Failure" Journal of Banking \& Finance, 10, 511-531.

Quigley, J (1987) "Interest Rate Variations, Mortgage Prepayments and Household Mobility" Review of Economics and Statistics, 69, 4, 636-644.

Rowley A, Gibson, V. and Ward, C (1996), Quality of urban design: a study of the involvement of private property decision-makers in urban design, London: Royal Institution of Chartered Surveyors.

Simons R (1994) "Industrial Real Estate Mortgage Default" Real Estate Economics, 22, 4, 631-646.

Tinic S, (1972), The Economics of Liquidity Services, Quarterly Journal of Economics, 86, 70-93.

Umlauf S (1993), "Transaction Taxes and Stock Market Behaviour: the Swedish Experience", Journal of Financial Economics, 33, 227-240.

Vandell K, Barnes W, Hartzell D, Kraft D and Wendt W (1993) "Commercial Mortgage Defaults: Proportional Hazards Estimation Using Individual Loan History" Real Estate Economics, 21, 4, 451-480.

Williams J (1997) “Redevelopment of Real Assets" Real Estate Economics 25, 1, 387-407. 